\title{
Surgical reconstruction of the musculocutaneous nerve in traumatic brachial plexus injuries
}

Madjid Samii, M.D., Gustavo A. Carvalho, M.D., Guido Nikkhah, M.D., Ph.D., and Götz Penkert, M.D.

Departments of Neurosurgery, Nordstadt Hospital and Medical School, Hannover, Germany

Over the last 16 years, 345 surgical reconstructions of the brachial plexus were performed using nerve grafting or neurotization techniques in the Neurosurgical Department at the Nordstadt Hospital, Hannover, Germany. Sixty-five patients underwent graft placement between the C-5 and C- 6 root and the musculocutaneous nerve to restore the flexion of the arm. A retrospective study was conducted, including statistical evaluation of the following pre- and intraoperative parameters in 54 patients: 1) time interval between injury and surgery; 2) choice of the donor nerve (C-5 or C-6 root); and 3 ) length of the grafts used for repairs between the C-5 or C-6 root and the musculocutaneous nerve.

The postoperative follow-up interval ranged from 9 months to 14.6 years, with a mean \pm standard deviation of $4.4 \pm 3$ years. Reinnervation of the biceps muscle was found in $61 \%$ of the patients. Comparison of the different preoperative time intervals (1-6 months, 7-12 months, and >12 months) showed a significantly better outcome in those patients with a preoperative delay of less than 7 months ( $p$ $<0.05)$. Reinnervation of the musculocutaneous nerve was demonstrated in $76 \%$ of the patients who underwent surgery within the first 6 months postinjury, in $60 \%$ of the patients with a delay of between 6 and 12 months, and in only $25 \%$ of the patients who underwent surgery after 12 months. Comparison of the final outcome according to the root $(\mathrm{C}-5$ or $\mathrm{C}-6)$ that was used for grafting the musculocutaneous nerve showed no statistical difference.

Furthermore, statistical analysis (regression test) of the length of the grafts between the donor (C-5 or C-6 root) nerve and the musculocutaneous nerve displayed an inverse relationship between the graft length and the postoperative outcome.

Together, these results provide additional information to enhance the functional outcome of brachial plexus surgery.

Key Words * brachial plexus * musculocutaneous nerve * graft * nerve reconstruction * nerve grafting

In traumatic lesions of the brachial plexus, disruption of the nerve structures may occur at the level of the roots (intra- or extraspinal), trunk, cord, peripheral nerves, or in various combinations $[2,3,5,6]$ and this usually results in severely disabling symptoms and physical handicaps. $[1,39,40]$ Consideration of the surgical management needed to improve the restoration of function to part of the injured brachial plexus 
seems to be strongly warranted. The strategies used to reconstruct the brachial plexus mainly include peripheral nerve grafting and/or neurotization. Neurotization of the brachial plexus is usually accomplished using the intercostal, accessory, or in some special cases the phrenic nerve. $[4,9,21,28,35,36]$ Despite the improvement over the last decade in surgical techniques for the brachial plexus, surgical outcome and functional restoration of the affected arm is still very limited. $[8,11,18,29]$ In fact, the complete restoration of the arm's function is almost impossible in the majority of severe traction injuries of the brachial plexus. Avulsion of all the cervical nerve roots is often present after such traumatic injuries and therefore surgical reconstruction is restricted to the main functions of the arm that can be successfully repaired.[31,41] Nerve grafting to the musculocutaneous nerve is undoubtedly one of the main goals of surgical management. [33,39,47]

Surgical outcomes in brachial plexus surgery may depend on different pre- and intraoperative parameters. The time interval between injury of the brachial plexus and surgery, the extent of the lesion, the choice of the donor nerve for grafting, and the surgical technique are the most important factors that play a role in the final outcome.

Statistical analysis of these different parameters has been largely absent and may help to optimize the surgical results in the management of brachial plexus lesions.

\section{CLINICAL MATERIAL AND METHODS}

Between 1978 and 1994, 345 patients with traumatic injuries of the brachial plexus were surgically treated in the Neurosurgical Department at the Nordstadt Hospital in Hannover, Germany. All patients were treated with grafting and/or a neurotization of the brachial plexus. A careful retrospective analysis of these cases revealed that grafts were placed between the C-5 or C- 6 root and the musculocutaneous nerve in 65 patients. Motorcycle accidents were the primary cause of the injury in $90 \%$ of these patients. All patients were first conservatively treated with intensive physiotherapy and were referred to our clinic because of incomplete or absent recovery of the brachial plexus. Despite our policy of treating patients who do not experience spontaneous recovery between 3 and 6 months postinjury, many patients were admitted later than 6 months after their accident.

Neurological examination demonstrated a complete palsy of the brachial plexus in 40 patients, and a complete upper brachial plexus injury in only 25 . Electromyography was performed in all patients at admission to detect spontaneous reinnervation of the biceps muscle. In all cases electrophysiological studies failed to demonstrate signs of biceps reinnervation.

Of these 65 patients, there were 55 males and 10 females, aged 16 to 49 years, with a mean age of 25 years. The time between the traumatic injury of the brachial plexus and the operation ranged from 2 to 14 months, with a mean of 8 months ( \pm 2 standard deviations).

Surgery was performed via a standard supra- and infraclavicular approach. Cervical roots were exposed at the supraclavicular region and followed as far as their entrance into the intervertebral foramen to assure their extraspinal integrity. Integrity of the cervical roots and viability for grafting were also evaluated with the aid of microscopy and electrical root stimulation, with recording of somatosensory evoked potentials from the sensory cortex by subdermal needle electrodes. In patients with extensive root fibrosis or negative somatosensory evoked potential stimulation, no grafting was performed and neurotization of the brachial plexus was preferred. In almost all cases, lesion of the brachial plexus occurred at the supraclavicular level. 
After evaluation of the cervical roots, the musculocutaneous nerve was exposed in the infraclavicular region at its origin from the lateral cord. Whenever possible, this nerve was followed upward into the lateral cord to decrease the graft distance between the root (C-5 or C-6) and the musculocutaneous nerve. One or two sural grafts were placed between the root and the musculocutaneous nerve. The graft was placed from the supraclavicular to the infraclavicular region under the clavicle and the minor pectoral muscle, and sutured with the aid of an operating microscope (Fig. 1).

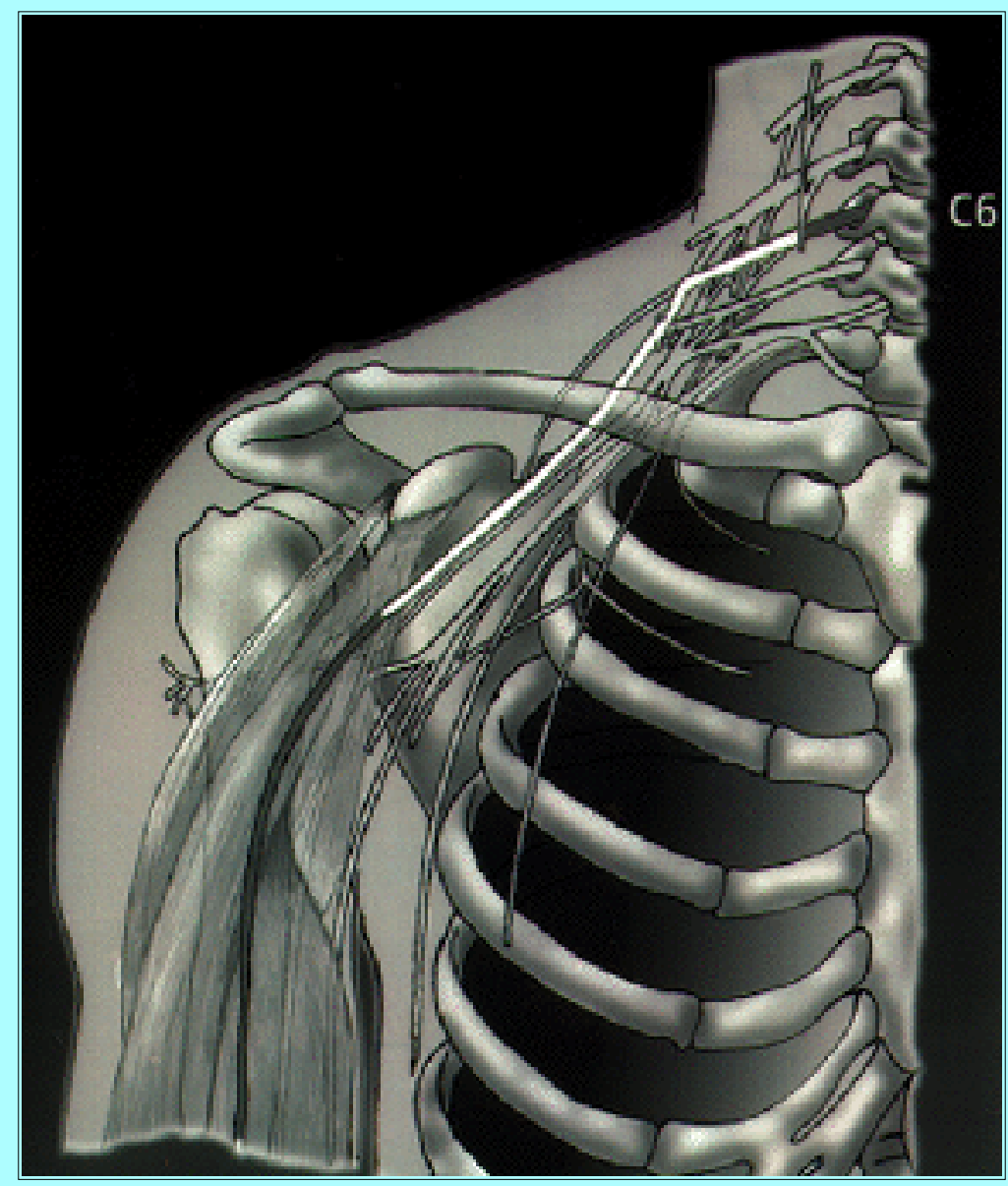

Fig. 1. Drawing displaying a single sural graft placed between the C-6 root and the musculocutaneous nerve (highlighted in white).

Postoperative follow-up review was performed 6 to 8 months postsurgery and yearly thereafter. Evaluation of the recuperation of biceps strength was performed according to the Medical Research Council (MRC) scale for muscle power grading (British system, MRC scale, M1-M5).[8]

\section{Statistical Analysis}

The statistical analysis was performed using commercially available software (Statview 4.5; Abacus Concept Inc., Berkeley, CA). The following statistical tests were performed: 1) mean, maximum, and minimum values; 2) analysis of variance test with Fisher's protected least significant difference post-hoc test; and 3) linear regression analysis. A probability value less than 0.05 was considered significant.

To detect the main factors that could influence the postoperative surgical results, the following different pre- and intraoperative parameters were analyzed: 1) time interval between injury and surgery; 2) the choice of donor nerve (C-5 or C-6) used for the reconstruction (grafting) of the musculocutaneous nerve; and 3 ) length of the nerve grafts. 
For evaluation of the influence of the time interval between injury and surgery, the patients were divided into three main groups: Group I, time interval from 1 to 6 months; Group II, time interval from 7 to 12 months; and Group III, time interval longer than 12 months.

\section{Postoperative Results}

Of the 65 patients in whom reconstruction (grafting) of the musculocutaneous nerve was performed, 11 had a follow-up period of less than 9 months and were therefore excluded from this analysis. The remaining 54 patients, with follow-up periods ranging from 9 months to 14.6 years (mean $4.4 \pm 3$ years, standard deviation) were statistically evaluated. Overall, reinnervation of the biceps muscle was achieved in $61 \%$ of the cases. However, when only the patients with a follow-up period of at least 3 years were analyzed, reinnervation of the musculocutaneous nerve was found in $70 \%$ of the cases.

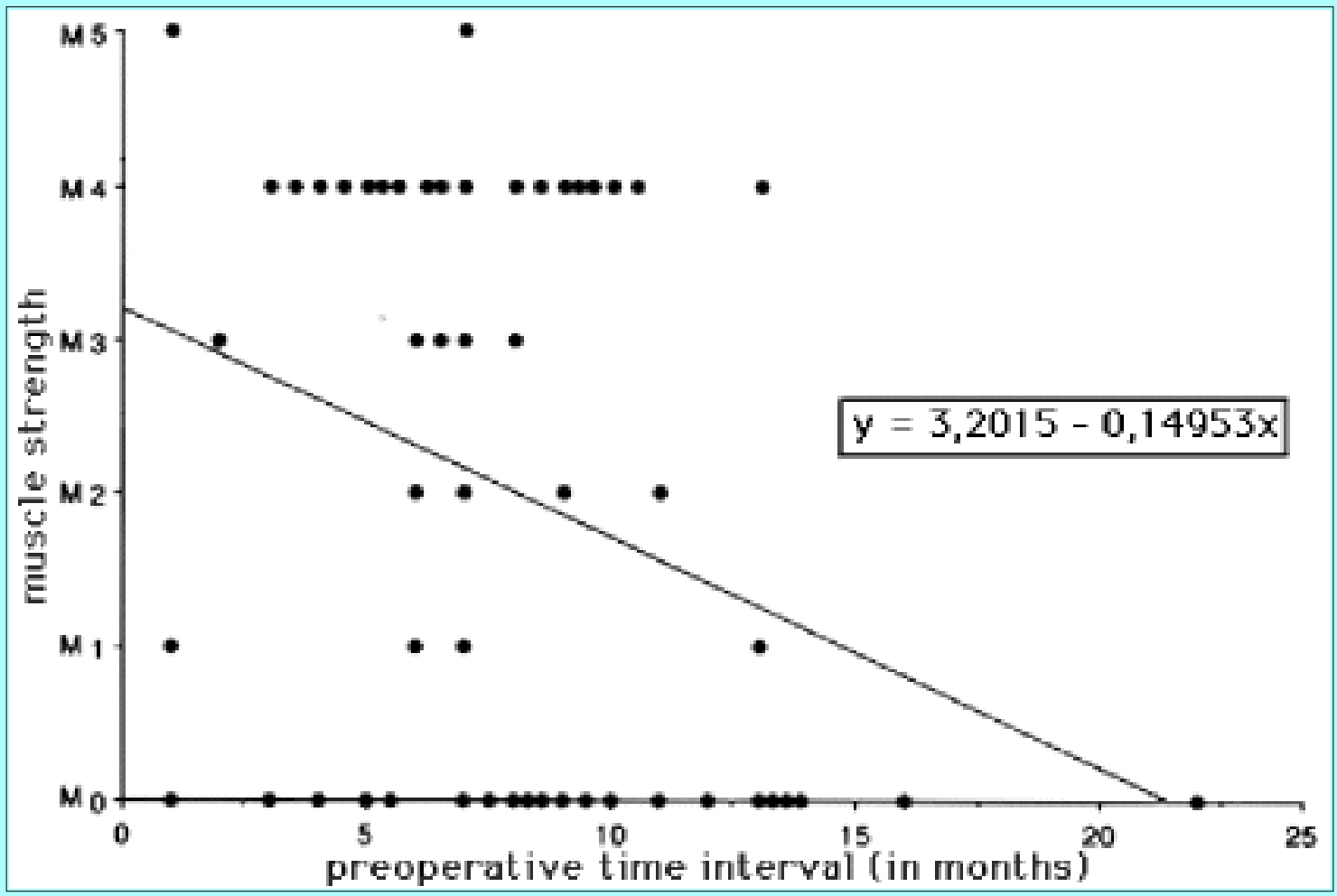

Fig. 2. Scatterplot of linear regression analysis showing the relation between the time interval from trauma to surgery and the surgical result (MRC scale). For the most part, the best final results were obtained in patients who underwent surgery between 2 and 6 months postinjury.

\section{Preoperative Time Interval}

Evaluation of the postoperative results according to the time between injury and surgery to graft the musculocutaneous nerve showed a better outcome for patients who underwent surgery soon after the injury to the brachial plexus (Fig. 2). Seventy-six percent of patients in Group I showed signs of reinnervation (M1-M5) of the biceps muscle. Functional reinnervation (M3-M5) was found in 62\% of the patients. Sixty percent of patients in Group II showed a biceps strength from M1 to M5 and 44\% experienced functional reinnervation. In contrast, patients in Group III displayed a markedly reduced reinnervation rate of $25 \%$ and only $12.5 \%$ experienced functional reinnervation of the biceps muscle (Table 1). 


\begin{tabular}{|c|c|c|c|c|c|c|c|}
\hline \multirow[b]{3}{*}{$\begin{array}{l}\text { Time Interval } \\
\text { Postinjury }\end{array}$} & \multicolumn{7}{|c|}{$\begin{array}{l}\text { TABLE } 1 \\
\text { NTERVAL BETWEEN IN.URV AND SURGERV } \\
\text { MUSCULOCUTANEOUS NERVE WITH } \\
\text {-6 ROOT IN } 54 \text { PATIENTS* }\end{array}$} \\
\hline & \multicolumn{6}{|c|}{ MRC scale } & \multirow[b]{2}{*}{$\begin{array}{l}\text { No. of } \\
\text { Cases }\end{array}$} \\
\hline & $\mathrm{M} 0$ & M1 & $\mathrm{M} 2$ & M3 & M4 & M5 & \\
\hline $\begin{array}{l}0-6 \operatorname{mos} \\
7-12 \operatorname{mos} \\
>-12 \operatorname{mos}\end{array}$ & $\begin{array}{r}5 \\
10 \\
6\end{array}$ & $\begin{array}{l}2 \\
1 \\
1\end{array}$ & $\begin{array}{l}1 \\
3 \\
0\end{array}$ & $\begin{array}{l}3 \\
2 \\
0\end{array}$ & $\begin{array}{l}9 \\
8 \\
1\end{array}$ & $\begin{array}{l}1 \\
1 \\
0\end{array}$ & $\begin{array}{r}21 \\
25 \\
8\end{array}$ \\
\hline \multicolumn{8}{|c|}{$\begin{array}{l}\text { "Mean follow-up period }=4.4 \pm 3 \text { years. } \\
t \text { Values are gi ien according to the MRC scale for musde power grading } \\
\text { (Eritish system). }\end{array}$} \\
\hline
\end{tabular}

The comparison between the different time intervals demonstrated that patients with a preoperative time interval of between 1 and 6 month achieved a significantly better result than patients who underwent surgery after 12 months ( $<$ < 0.05) (Fig. 3). Despite the better outcome in cases of early surgery, statistical analysis failed to demonstrate a significant difference between Groups I and II ( $\mathrm{p}=0.28)$ (Fig. $4)$.

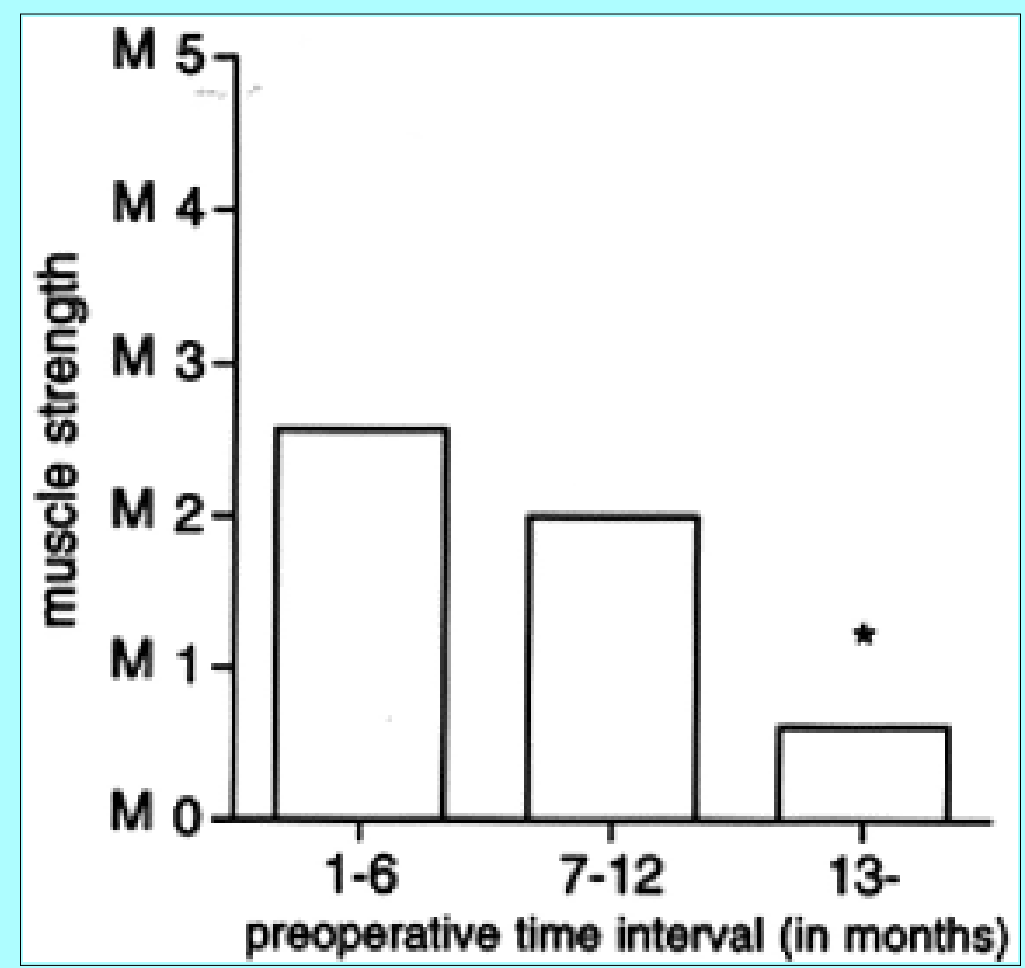

Fig. 3. Bar graph comparing the different preoperative time intervals and the achieved strength of the biceps muscle (MRC scale). Note the significantly poorer results (asterisk) in the group of patients who underwent surgery 13 months postinjury, compared with those who underwent earlier operations.

\section{Donor Nerves}

Reconstruction of the musculocutaneous nerve was accomplished with the C-5 root in 25 patients and with the C-6 root in 29. Grafting of the musculocutaneous nerve with the C-5 or C- 6 root resulted in reinnervation of the biceps muscle (M1-M5), despite the preoperative time interval, in $68 \%$ and 55\% of cases, respectively. Statistical evaluation taking into account the choice of donor nerves showed no 
significant difference in the postoperative results. Thus, further analysis was performed with all patients considered as a single group.

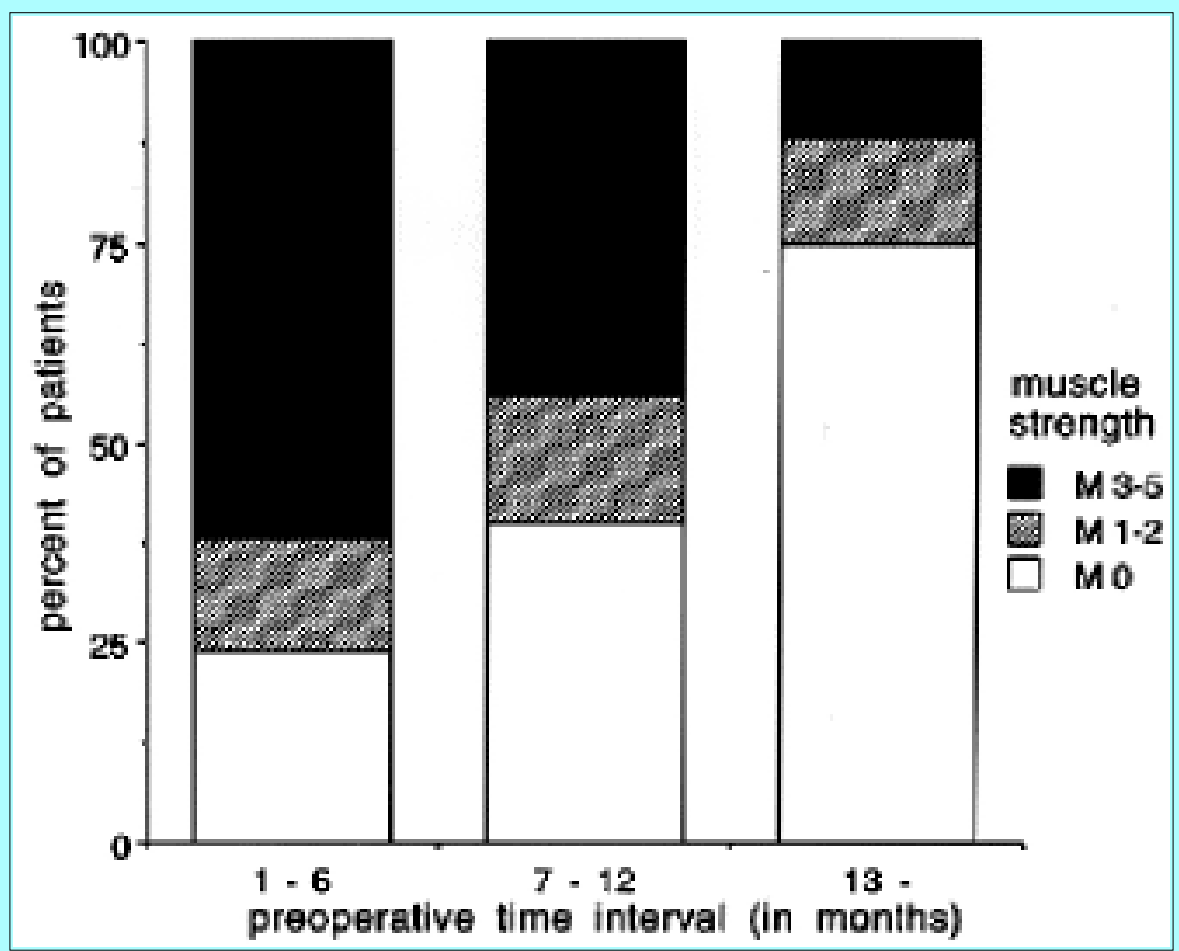

Fig. 4. Bar graph comparing the functional and nonfunctional restoration of biceps strength (MRC scale) according to the different preoperative time interval. A better functional recovery was achieved in the patients who underwent surgery between 1 and 6 months postinjury, compared with those undergoing operation later.

\section{Length of the Nerve Grafts}

Grafting between the C-5 or C- 6 root and the musculocutaneous nerve was performed using sural nerves with a mean length of $12.4 \pm 3.15 \mathrm{~cm}$. Linear regression analysis demonstrated a worse postoperative result in cases in which longer sural grafts were used (Fig. 5). 


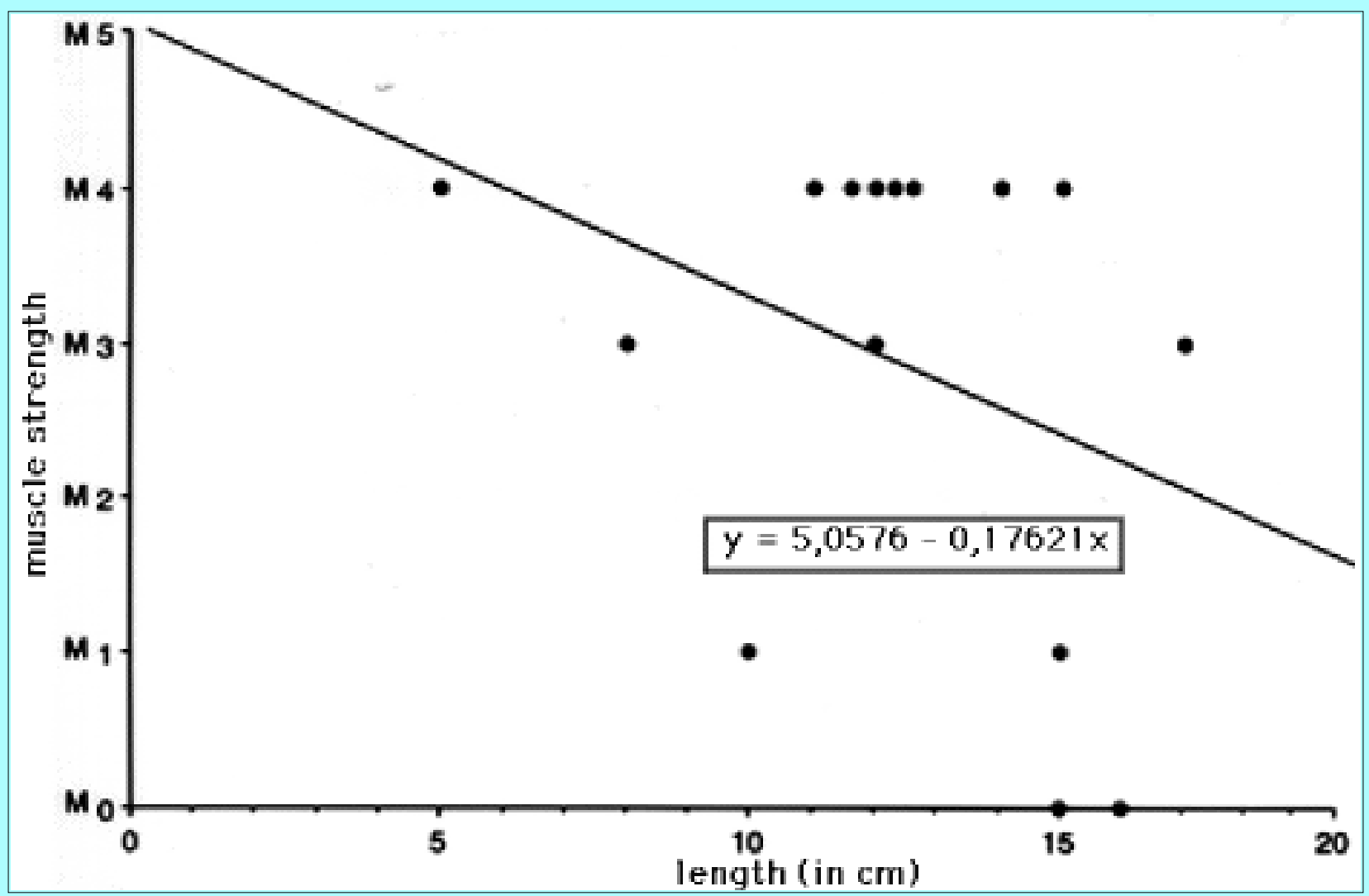

Fig. 5. Scatterplot of linear regression analysis showing better postoperative results (MRC scale) with shorter nerve grafts used for repair between the C-5 or C-6 root and the musculocutaneous nerve.

Statistical comparison between the patients with nerve grafts of $12 \mathrm{~cm}$ or shorter and those with grafts longer than $12 \mathrm{~cm}$ demonstrated that patients with shorter grafts experienced a slightly better outcome than those with longer grafts, as shown in Fig. 6. However, this difference did not reach statistical significance $(\mathrm{p}=0.07)$.

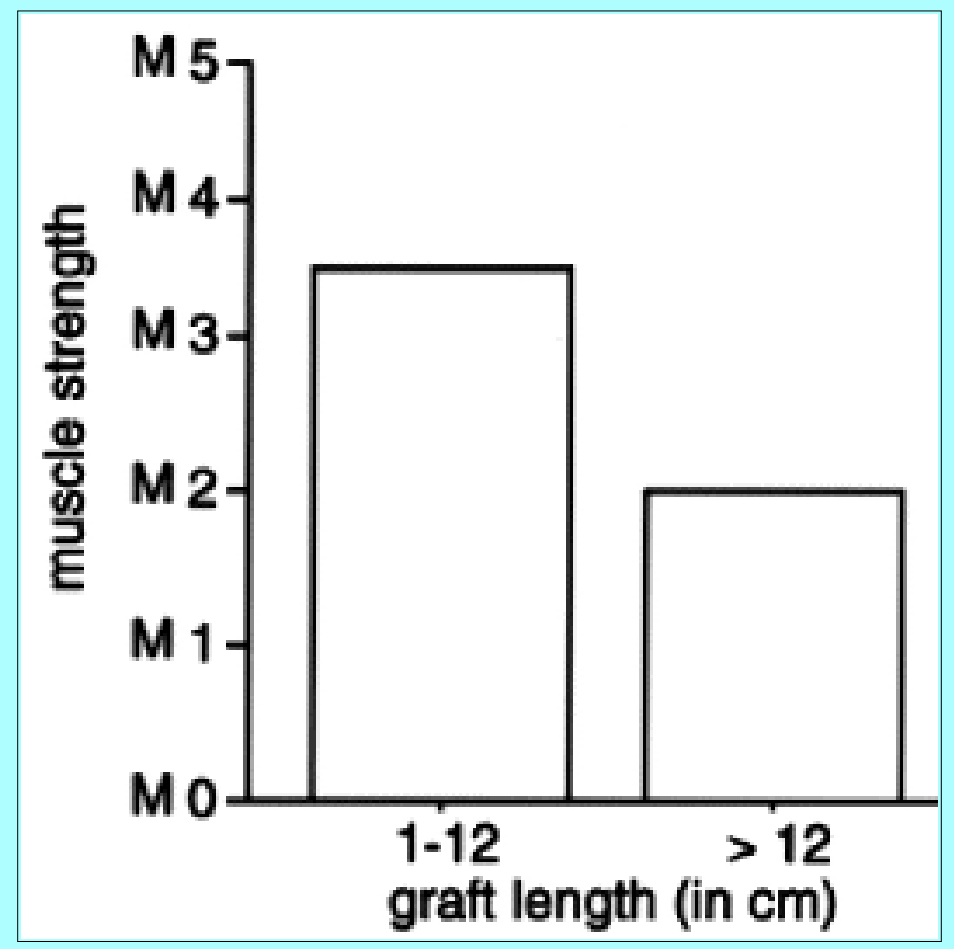


Fig. 6. Bar graph showing the better surgical results (MRC scale) achieved with shorter nerve grafts $(1-12 \mathrm{~cm})$. No statistically significant difference was found between these two groups $(1-12$ and $>12 \mathrm{~cm}, \mathrm{p}<0.05)$.

\section{DISCUSSION}

The majority of cases of traumatic injury of the brachial plexus are the result of car and motorcycle accidents.[6,8,18] There are two main mechanisms for the traumatic lesion of the brachial plexus: 1) direct injury of the nerves (for example, clavicular fracture); or 2) the traction and consequent avulsion of the cervical nerve roots from the spinal cord.[1,18,27,32] In cases of avulsion of the cervical nerve roots, surgical management is based on neurotization of the most important nerves of the brachial plexus via intercostal, accessory, or phrenic nerves.[15,31,35,36,39] However, C-5 and C-6 roots are still in continuity in a great number of patients, and therefore can be used for the reconstruction of the musculocutaneous, suprascapular, and axillary nerves, for example. Experience in the surgical management of patients with traumatic lesions of the brachial plexus shows that recovery of elbow flexion and stabilization of the shoulder are the main surgical objectives.[4,16,19,23,26,45] Although many reports have been published in the literature regarding the surgical reconstruction of the musculocutaneous nerve (elbow flexion), statistical analyses have not been conducted to study the different factors that influence the surgical results in these patients. In fact, many distinct pre- and intraoperative parameters have been thought to influence the final surgical outcome.[17,27,47]

Among these parameters, the time interval between the injury of the brachial plexus and the surgery, the proximal donor nerve used for the reconstruction of the peripheral nerve, the length of the grafts, and the surgical technique have been thought to influence the final functional outcome. The assembly of a homogeneous group of patients for evaluation of each parameter separately is extremely difficult and can only be achieved in a large series of cases.

\section{Time Interval Between Trauma and Surgery}

The time interval between the lesion (trauma) and surgery is one of the most important factors determining the final surgical result.[10,34,46] Over the last few years many authors have been advocating early (4-6 months postinjury) surgical exploration of the brachial plexus.[22,30] Narakas $[28,29]$ demonstrated in his series that the surgical results from reconstruction and neurotization of the brachial plexus worsen substantially if the surgery is performed 8 to 12 months postinjury. Millesi[23-26] has also stressed the importance of early exploration of the brachial plexus in patients with no signs of spontaneous regeneration, and he has divided the preoperative time interval into an early (3-6 months) and late phase of direct repair (6-12 months). Probably one of the main factors responsible for the poor results produced by late repair is the progressive degeneration of the muscle fibers, formation of fibrosis and scar tissue within the muscle, and the distal degeneration of the nerve.[27,33] Histopathological studies demonstrate signs of muscle degeneration as early as 3 to 4 weeks postinjury and the complete replacement of the muscle fibers by scar tissue after 2 to 3 years.[20,21,24] Surgical findings in such cases are usually an atrophic muscle with some ischemic signs.[31,33] Furthermore, the lack of movement in the affected arm may commonly lead to arthrosis of the elbow, hand, and finger joints that will handicap the final surgical result, even in cases of good postoperative muscle reinnervation.

Our results demonstrate a significantly impaired functional outcome in patients who underwent surgery after 12 months compared with those who underwent surgery earlier (1-6 months). However, in 
correlating the final results in patients treated surgically between 7 and 12 months with patients treated after 12 months, no significant difference could be found.

Narakas[27-30] also reported better results in patients undergoing early operation. Nevertheless, he reported sporadic good results in patients who underwent very late operations (up to 3 years). In our series, we have also observed some isolated cases of proximal muscle reinnervation in patients who underwent surgery 12 to 18 months postinjury. However, in the majority of the cases, reinnervation was usually minor to moderate with no useful functional recovery of the reinnervated muscle.

\section{Donor Nerves}

Radiological and surgical findings demonstrate the avulsion of C-7 and C-8 roots in approximately 50 to $75 \%$ of the traction injuries of the brachial plexus.[7,9] Therefore, C-5 and/or C-6 roots are common nerve donors for reconstruction of the brachial plexus.[5,21] Narakas[27] showed better results for the reconstruction of the brachial plexus using the C-5 compared with the C-6 root as the donor nerve. However, the author compared very heterogeneous groups of patients who also had different preoperative time intervals. The analysis of our patients who underwent reconstruction of the musculocutaneous nerve after a similar preoperative time interval between injury and surgery failed to show a significant difference between the C-5 and C- 6 nerve roots.

Based on the fact that both $\mathrm{C}-5$ and $\mathrm{C}-6$ roots have almost the same number of motor fibers (approximately 25,000) and that just $25 \%$ of a cervical root may be enough for the reconstruction of the musculocutaneous nerve (approximately 6000 motor fibers), it is unlikely that the final surgical result would differ between these roots.[27,28] Thus, regarding the donor nerve used, it seems that the main limiting factor is not which cervical root is used for grafting but the "quality" of the root. Actually, retrograde degeneration of the cervical roots posttrauma, which may occur in approximately 15 to $80 \%$ of the nerve fibers, and further development of scar tissue within and around the nerve structures are the main drawbacks in relation to the final surgical outcome.[28-30]

\section{Length of the Nerve Grafts}

Experimental work in the 1970s showed no correlation between the length of the nerve grafts and the final surgical results in the reconstruction of the brachial plexus.[37,38,44] Graft vascularization, for example, occurs not from the proximal nerve donor but from the surrounding tissue. $[12,14,44]$ Thus, compared with short grafts, longer grafts will not suffer from more ischemic events. On the other hand, nerve grafts with larger diameters will have a tendency to establish an insufficient vascularization compared with small diameter grafts. Our analysis of the length of the grafts used to reconstruct the musculocutaneous nerve found that patients with grafts shorter than $12 \mathrm{~cm}$ experienced a better result. One underlying reason may be that the extent of the brachial plexus lesion was smaller in these cases than in cases in which longer grafts were necessary. Therefore, the length of the graft may be taken as an indicator for the extent of the injury, which also determines the chances for a functional recovery.

Regarding the microsurgical technique use in the reconstruction of the brachial plexus, experimental and clinical studies have demonstrated that results will be most affected by the surgical technique. $[2,3,13,23,28,43]$ A poor coaptation and tension at the nerve union site will stimulate the proliferation of scar tissue and further development of fibrosis and granulomas at that location, which may impair the regeneration of growing axons.[25,37,42,43] 
Our statistical evaluation, which was guided by the different parameters that might play an important role in the reconstruction (grafting) of the musculocutaneous nerve after traumatic injury to the brachial plexus, revealed the following points: 1) in cases without spontaneous reinnervation, surgery should be performed within 4 to 6 months postinjury; 2) surgical results do not differ or depend on the donor nerve C-5 or C- 6 but on the intraoperative condition of the roots (presence of scar tissue or degeneration); 3 ) the length of the grafts used will indirectly influence the final result because graft length represents the extent of the brachial plexus injury; and 4) one of the major points regarding surgical technique is that perfect coaptation with no tension at the nerve union site should always be attempted.

\section{References}

1. Allieu Y: Exploration et traitement direct des lésions nerveuses dans les paralysies traumatiques du plexus brachial chez l'adulte. Rev Chir Orthop 63:107-122, 1977

2. Alnot JY, Daunois O, Oberlin C, et al: Les paralysies totales du plexus brachial par lésions supra-claviculaires. Rev Chir Orthop 78:495-504, 1992

3. Alnot JY, Jolly A, Frot B: Traitement direct des lésions nerveuses dans les paralysies traumatiques du plexus brachial chez l'adulte. A propos d'une serie de 100 cas opérés. Int Orthop 5:151-168, 1981

4. Berger A, Becker MHJ: Brachial plexus surgery: our concept of the last twelve years. Microsurgery 15:760-767, 1994

5. Carvalho GA, Nikkhah G, Matthies C, et al: Diagnosis of root avulsions in traumatic brachial plexus injuries: the value of computerized tomography myelography and magnetic resonance imaging. $\mathbf{J}$ Neurosurg 86:69-76, 1997

6. Clarke D, Richardson P: Peripheral nerve injury. Curr Opin Neurol 7:415-421, 1994

7. Comtet JJ, Sedel L, Fredenucci JF, et al: Duchenne-Erb palsy. Experience with direct surgery. Clin Orthop 237:17-23, 1988

8. Davis P: Managing brachial plexus injuries. Nurs Stand 8:31-34, 1994

9. Dolenc VV: Contemporary treatment of peripheral nerve and brachial plexus lesions. Neurosurg Rev 9:149-156, 1986

10. Dubuisson A, Kline DG: Indications for peripheral nerve and brachial plexus surgery. Neurol Clin 10:935-951, 1992

11. Ferraresi S, Garozzo D, Griffini C, et al: Brachial plexus injuries. Guidelines for management: our experience. Ital J Neurol Sci 15:273-284, 1994

12. Fesser Z, Radek A, Sokolowski Z: [Comparative evaluation of using autologous cable transplants and the classical microsurgical method of nerve anastomosis.] Neurol Neurochir Pol 25:208-213, 1991 (Pol)

13. Fisher TR: Nerve injury. Injury 21:302-304, 1990

14. Freilinger G, Gruger H, Holle J, et al: Zur Methodik der 'senso-motorisch' differenzierten Faszikel-naht peripherer Nerven. Handchirurgie 7:133-137, 1975 
15. Glasby MA, Hems TEJ: Repairing spinal roots after brachial plexus injuries. Paraplegia 33:359-361, 1995

16. Harat M, Radek A: [Management tactics in brachial plexus injuries.] Neurol Neurochir Pol 27:829-837, 1993 (Pol)

17. Henke R: Mikrochirurgische Rekonstruktion des Plexus brachialis. Zentralbl Chir 110:749-757, 1985

18. Hentz VR, Narakas A: The results of microneurosurgical reconstruction in complete brachial plexus palsy. Assessing outcome and predicting results. Orthop Clin North Am 19:107-114, 1988

19. Jamieson A, Hughes S: The role of surgery in the management of closed injuries to the brachial plexus. Clin Orthop 147:210-215, 1980

20. Kline DG: Macroscopic and microscopic concomitants of nerve repair. Clin Neurosurg 26:582-606, 1979

21. Kline DG, Judice DJ: Operative management of selected brachial plexus lesions. J Neurosurg 58:631-649, 1983

22. Mehta VS, Banerji AK, Tripathi RP: Surgical treatment of brachial plexus injuries. Br J Neurosurg 7:491-500, 1993

23. Millesi H: Brachial plexus injuries. Nerve grafting. Clin Orthop 237:36-42, 1988

24. Millesi H: Die chirurgische Behandlung der traumatischen Plexus brachialis-Läsionen. Orthopade 16:434-440, 1987

25. Millesi H: Interfascicular grafts for repair of peripheral nerves of the upper extremity. Orthop Clin North Am 8:387-404, 1977

26. Millesi H: Widerherstellung durchtrennter peripherer Nerven und Nerventransplantation. Munchen Med Wochenschr 111:2669-2674, 1969

27. Narakas A: Indications et résultats du traitement chirurgical direct dans les lésions par élongation du plexus brachial. I--Les indications du traitement chirurgical direct. Rev Chir Orthop 63:88-106, 1977

28. Narakas A: Neurotization or nerve transfer for brachial plexus lesions. Ann Chir Main 1:101-108, 1982

29. Narakas A: The treatment of brachial plexus injuries. Int Orthop 9:29-36, 1985

30. Narakas AO: The surgical treatment of traumatic brachial plexus lesions. Int Surg 65:521-527, 1980

31. Oberlin C, Béal D, Leechavengvongs S, et al: Nerve transfer to biceps muscle using a part of ulnar nerve for C5-C6 avulsion of the brachial plexus: anatomical study and report of four cases. J Hand Surg (Am) 19:232-237, 1994

32. Päzolt HJ: Mikrochirurgische Behundlung von Armplexusverletzungen. Zentralbl Chir 111:589-596, 1986 
33. Penkert G: Beurteilung und Behandlung peripherer Nervenverletzung. giatros (Neurologie) 7:57-64, 1991

34. Penkert G: Periphere Nervenverletzungen--aktueller Behandlungsstandard. Zentralbl Neurochir 54:47-51, 1993

35. Penkert G, Carvalho GA, Nikkhah G, et al: Reinnervation bei Wurzelausrissen des Plexus brachialis mittels des N. accessorius als Spendernerv, in Berghaus A (ed): Plastische und

Wiederherstellungschirurgie. Reinbeck: Einhorn-Presse Verlag, 1996, pp 468-470

36. Samardzic M, Sekulovic N, Grujicic D: Mikrohirursa rekonstrukcija ozledjenih perifernih zivaca. Srp Arh Celok Lek 119:14-17, 1991

37. Samii M: Interfasziculäre autologe Nerventransplantationen. Indikation, Technik und Ergebnisse. Deutches Ärztebl 70:1257-1262, 1972

38. Samii M: Use of microtechniques in peripheral nerve surgery--experience with over 300 cases, Handa H (ed): Microneurosurgery. Tokyo: Igoku Shoin, 1975, pp 85-92

39. Samii M, Carvalho GA, Nikkhah G, et al: Neurotization des Plexus brachialis: Interkostalennerven mit dem N. musculocutaneous, in Berghaus A (ed): Plastische und Wiederherstellungschirurgie. Reinbeck: Einhorn-Presse Verlag, 1996, pp 471-472

40. Samii M, Carvalho GA, Nikkhah G, et al: Zur funktionellen Rekonstruktion des N. axillaris bei traumatischen Armplexus-Läsionen, in Berghaus A (ed): Plastische und Wiederherstellungschirurgie. Reinbeck: Einhorn-Presse Verlag, 1996, pp 466-467

41. Samii M, Kahl RI: Klinische Resultate der autologen Nerventransplantationen. Med Mitt 46:197-202, 1972

42. Samii M, Schürmann K, Scheinpflug W, et al: Experimental studies comparing grafting with autogenous and irradiated freeze dried homologous nerves. Excerpta Medica (Intl Congress Series) 287:263-266, 1971

43. Samii M, Wallenborn R: Tierexperimentelle Untersuchungen über den Einflüss der Spannung auf den Regenerationserfolg nach Nervennaht. Acta Neurochir 27:87-110, 1972

44. Seddon HJ: Surgical Disorders of the Peripheral Nerves. London: Churchill Livingstone:1975

45. Sedel L: Repair of severe traction lesions of the brachial plexus. Clin Orthop 237:62-66, 1988

46. Sedel L: The results of surgical repair of brachial plexus injuries. J Bone Joint Surg (Br) 64:54-66, 1982

47. Thomeer RT: Recovery of brachial plexus injuries. Clin Neurol Neurosurg 93:3-11, 1991

Manuscript received December 23, 1996.

Accepted in final form June 5, 1997.

Address reprint requests to: Gustavo A. Carvalho, M.D., Neurochirurgische Klinik-Krankenhaus 
Nordstadt, Haltenhoffstrasee 41, 30167 Hannover, Germany. 